\title{
Validação de nova proposta de espermocultura quantitativa aplicada a sêmen industrializado de touros
}

[Validation of a new proposal of quantitative sperm culture for industrialized bull semen]

\author{
A.F. Carvalho ${ }^{1}$, A. Saragó ${ }^{1}$, S.S. Azevedo ${ }^{2}$, C.S.A. Batista ${ }^{3}$, E. Scarcelli ${ }^{1}$, M.E. Genovez ${ }^{1}$ \\ ${ }^{1}$ Instituto Biológico - Centro de Pesquisa e Desenvolvimento de Sanidade Animal - São Paulo, SP \\ ${ }^{2}$ Universidade Federal de Campina Grande - Campina Grande, PB \\ ${ }^{3}$ Universidade de São Paulo - Faculdade de Medicina Veterinária e Zootecnia - São Paulo, SP
}

\begin{abstract}
RESUMO
O Ministério da Agricultura, Pecuária e Abastecimento (MAPA) tem discutido a obrigatoriedade da realização de espermocultura em sêmen industrializado não somente para garantia da biossegurança mas também por falhas na fertilização in vitro pela contaminação dos ovócitos com bactérias ubiquitárias e oportunistas da microbiota prepucial. A técnica quantitativa de Pour Plate, preconizada pela Organização Internacional de Epizootias, é operacionalmente difícil e de custo elevado para a rotina em centrais de inseminação artificial (CIAs). Desse modo, avaliou-se a técnica de contagem de bactérias viáveis por superfície (CBVS) em UFC/mL de sêmen industrializado de touros de CIAs, comparando-a à técnica de Pour Plate, com intuito de validação. Foram empregadas palhetas de sêmen de touros do Projeto Hungria do MAPA. A partir da diluição seriada de $10^{-1}$ a $10^{-5}$ do sêmem, foram empregadas, paralelamente, as técnicas de Pour Plate e CBVS. A média ou mediana de UFC/mL obtida em cada diluição foi comparada entre as técnicas, e não foram observadas diferenças estatísticas entre as duas técnicas quanto à quantificação de bactérias em UFC/mL, sugerindo a possibilidade de substituição da técnica de Pour Plate pela de CBVS, com vantagens de praticidade e menor custo.
\end{abstract}

Palavras-chave: Pour Plate, bactérias viáveis, espermocultura, sêmen industrializado, central de inseminação artificial

\begin{abstract}
The Brazilian Ministry of Agriculture (MAPA) has discussed the mandatory culture of industrialized semen, both to ensure biosefety, and to prevent in vitro fertilization problems caused by oocyte contamination with ubiquitous and opportunistic bacteria from preputial microbiota. Pour plate, a quantitative technique recommended by the World Organization for Animal Health (OIE), is operationally difficult and costly for routine analysis in Artificial Insemination Centers (AICs). The objectives of this study were to evaluate and validate viable superficial bacteria counts (VSBC), in CFU/mL, compared with pour plate counts, in industrialized bull semen samples from AICs. Semen straws from Projeto Hungria - MAPA bulls were used. VSBC and pour plate were carried out in parallel in serial dilutions of the samples, from $10^{-1}$ to $10^{-5}$. CFU/mL means or medians recorded in each dilution and technique were compared, and no statistical differences were observed between the two techniques regarding the quantification of bacteria in CFU/mL, suggesting that it may be possible to replace pour plate for CBSV, a cheaper and more practical technique.
\end{abstract}

Keywords: Pour Plate, viable superficial bacteria, sperm culture, industrialized semen, artificial insemination center

Recebido em 24 de agosto de 2011

Aceito em 23 de novembro de 2011

E-mail: linebio@gmail.com 


\section{INTRODUÇÃO}

A inseminação artificial com a criopreservação do sêmen vem desempenhando importante papel na melhoria da qualidade genética e na produtividade dos animais. Neste processo, o sêmen é depositado diretamente no útero, evitando o efeito bactericida da secreção cervicovaginal produzida no estro. Muitos patógenos ou os próprios agentes da microbiota da cavidade prepucial podem sobreviver aos processos de industrialização, desde a diluição até o congelamento, trazendo sérios riscos aos animais e, algumas vezes, à saúde pública, visto que agentes causadores de zoonoses podem estar presentes (Palit et al., 1986; Eaglesome e Garcia, 1992; Genovez et al., 1999).

A cavidade prepucial e o sêmen de touros apresentam microbiota muito variada, constituída por microrganismos não patogênicos (Coelho, 1976; Flatscher e Holzmann, 1984), os quais podem tornar-se oportunistas, resultando em diminuição da eficiência reprodutiva (Eaglesome et al., 1999). Embora existam controvérsias quanto à interferência de bactérias ubiquitárias sobre a qualidade do sêmen e sua capacidade fecundante, sob certas condições, bactérias oportunistas podem migrar pelo trato genital de touros, causando uretrite, vesiculite seminal ou epididimite, e alterar significativamente a capacidade fecundante do sêmen decorrente de intensa reação inflamatória e de patologias no espermatozoide. Além disto, a contaminação bacteriana pode competir pela utilização dos nutrientes naturais do sêmen e ainda infectar fêmeas, resultando em baixas taxas de concepção e altas taxas de mortalidade embrionária ou abortamento (Genovez et al., 1999).

Agentes patogênicos podem alcançar a cavidade prepucial e o sêmen por via ascendente nas doenças sexualmente transmitidas, como a campilobacteriose genital bovina e a tricomonose bovina, ou pela exposição a microrganismos externos (Genovez et al., 1986; Rodrigues, 1998; Genovez et al., 1999; Wentink et al., 2000; Prado e Pérez, 2005). Por outro lado, a contaminação do sêmen pode ocorrer por via descendente como consequência de enfermidades sistêmicas específicas do aparelho reprodutor. Entre as mais importantes, destacam-se brucelose, leptospirose, micoplasmoses, clamidofilose, histofilose, IBR,
BVD e língua azul. Dentre os agentes isolados de touros mantidos a campo e em centrais de inseminação artificial (CIAs) destacam-se como potencialmente patogênicos: Staphylococcus epidermidis, Streptococcus spp., Arcanobacterium pyogenes, Escherichia coli, Pseudomonas aeruginosa, Bacterium spp., Alcaligenes faecalis, Pseudomonas pyocynea, Proteus vulgaris, Micrococcus spp., Acinetobacter spp. e Bacillus spp. (Genovez et al., 1999).

Alguns países importadores exigem exames de sêmen visando à detecção de microrganismos ubiquitários e oportunistas como Pseudomonas spp., Proteus spp., Staphylococcus spp., Streptococcus spp. e Escherichia coli, além de alguns fungos e leveduras (Genovez et al., 1999; OIE, 2008). Dessa forma, faz-se necessário um rígido controle da condição sanitária dos touros e da qualidade do sêmen, desde a colheita até a conservação (Varner et al., 1998), utilizando-se métodos eficazes de diagnóstico (Eaglesome e Garcia, 1992).

A adição de antibióticos permite a redução da contaminação do sêmen, diminuindo a transmissão de doenças venéreas bacterianas e o risco do desenvolvimento de endometrites decorrentes da inseminação (Prado e Pérez, 2005), porém não exclui a possibilidade de aumento do número de estirpes resistentes (Genovez et al., 1999).

A técnica bacteriológica quantitativa de Pour Plate preconizada até 2005 pela Organização Mundial de Saúde Animal (OIE) é laboriosa e de custo elevado, o que a inviabiliza para o uso de rotina pelas CIAs. Considerando-se que a espermocultura quantitativa não é exame obrigatório na comercialização da partida de sêmen industrializado e que este tem sido imputado como causa das falhas da fertilização in vitro (FIV) em razão de contaminações dos ovócitos com bactérias ubiquitárias e oportunistas, objetivou-se avaliar a praticidade e o padrão de equivalência, com o propósito de validação, da técnica de contagem de bactérias viáveis por superfície em unidades formadoras de colônia por mililitro $(\mathrm{UFC} / \mathrm{mL})$ de sêmen industrializado de touros de CIAs, comparando-o à técnica quantitativa de Pour Plate (Office..., 2005). 


\section{MATERIAL E MÉTODOS}

Foram utilizadas palhetas de sêmen industrializado de touros, cedidas pelo Ministério da Agricultura, Pecuária e Abastecimento (MAPA), referentes ao Projeto Hungria do Programa de Desenvolvimento da Bovinocultura de Leite (Brasil, 2005).

Para a avaliação da microbiota contaminante do lote de palhetas de sêmen industrializado de touros do Projeto Hungria, mantidas em nitrogênio líquido, 10 palhetas representantes de cada ejaculado foram selecionadas aleatoriamente, descongeladas em temperatura ambiente e desinfetadas com álcool etílico a $70 \%$; suas extremidades foram cortadas com tesoura estéril (uma tesoura para cada palheta), e os conteúdos recolhidos individualmente em microtubo estéril. Dez microlitos de cada microtubo foram semeados em meio Tryptic Soy Agar (TSA; Difco) acrescido de 5\% de sangue desfibrinado de carneiro e incubados em estufa de aerobiose a $37^{\circ} \mathrm{C}$ por $48-72$ horas.

Uma vez que as palhetas empregadas na análise qualitativa do sêmen resultaram estéreis, foi realizada a contaminação experimental dessas amostras com cultivos de Staphylococcus spp., Streptococcus spp. e Acinetobacter spp. Esses agentes eram provenientes de espermoculturas de sêmen de touros doadores de CIAs brasileiras, realizadas pelo Laboratório de Doenças Bacterianas da Reprodução do Instituto Biológico, os quais foram selecionados por sua elevada frequência nos isolamentos.

Uma suspensão em solução salina estéril $0,9 \%$, $\mathrm{pH} 7,2$ foi preparada a partir de cada cultivo, a qual foi diluída de acordo com o tubo 1 da escala de MacFarland. Para a suspensão final contendo os três agentes, foi utilizado o volume de $1 \mathrm{~mL}$ de cada suspensão e diluído para $1 / 8$ do tubo 1 da escala MacFarland, sendo então inoculado $1 \mu \mathrm{L}$ para cada $200 \mu \mathrm{L}$ de sêmen.

A partir do sêmen contaminado experimentalmente, foram realizadas as técnicas de Pour Plate como preconizado pela Office... (2005) e a de contagem de bactérias viáveis por superfície, empregando-se 50 palhetas de sêmen provenientes de 25 touros, sendo duas palhetas de sêmen por ejaculado por touro, que foram submetidas às diluições de $10^{-1}$ a $10^{-5}(200 \mu \mathrm{L}$ de sêmen em $1800 \mu \mathrm{L}$ de solução salina estéril $0,9 \%)$.

De cada diluição de sêmen, $500 \mu \mathrm{L}$ foram transferidos para placas de Petri estéreis em duplicata (uma de cada palheta de sêmen do mesmo ejaculado), e adicionados $15 \mathrm{~mL}$ de meio TSA contendo 5\% de sangue desfibrinado de carneiro. As placas foram homogeneizadas por agitação circular, deixando-se solidificar em fluxo laminar; foram então incubadas em estufa de aerobiose a $37^{\circ} \mathrm{C}$ por $48-72$ horas. As diluições que apresentaram crescimento de até 300UFC foram selecionadas (Quinn et al., 1994), e a contagem das colônias seguiu o procedimento padrão da OIE, utilizando-se Colony Counter (Stuart Scientific - USA), multiplicando-se o número de $\mathrm{UFC} / \mathrm{mL}$ pelo fator de diluição. Por fim, foi contabilizada a média aritmética de cada diluição, por ejaculado. Os resultados foram expressos em $\mathrm{UFC} / \mathrm{mL}$.

De cada diluição de sêmen, $500 \mu \mathrm{L}$ foram semeados em toda superfície do meio TSA acrescido de $5 \%$ de sangue desfibrinado de carneiro, por meio de alça Drigalski, em duplicata (uma de cada palheta de sêmen do mesmo ejaculado), e incubados em estufa de aerobiose a $37^{\circ} \mathrm{C}$ por $48-72$ horas. $\mathrm{O}$ procedimento para contagem das colônias e expressão dos resultados foi realizado conforme descrito para a técnica de Pour Plate.

Para a análise estatística, foram quantificadas a média \pm desvio-padrão (caso os dados seguissem distribuição normal) ou medianatintervalo interquartil (sem distribuição normal) de UFC/mL dos ejaculados por diluição de cada técnica. Foi aplicado o teste de normalidade de Kolmogorov-Smirnov e, em seguida, empregado o teste $t$ para dados com distribuição normal, ou teste U de Mann-Whitney para dados sem distribuição normal (Massad et al., 2004; Zar, 1999). Quando as diluições resultaram em quantidade de UFC incontáveis em uma ou nas duas técnicas, as amostras foram excluídas da análise estatística, sendo selecionadas apenas as que apresentaram crescimento de até 300UFC. As análises foram realizadas com os programas SPSS versão 13.0 for Windows, e o nível de significância adotado foi de $5 \%$. 


\section{RESULTADOS}

As palhetas empregadas na análise qualitativa do sêmen resultaram estéreis, portanto foi realizada a contaminação experimental dessas amostras com agentes encontrados frequentemente em espermoculturas de sêmen de touros doadores de CIAs brasileiras.

Foi padronizada uma suspensão em solução salina estéril $0,9 \%$ com cultivos de Staphylococcus spp., Streptococcus spp. e Acinetobacter spp., diluída $1 / 8$ do tubo 1 da escala MacFarland. Um microlitro dessa suspensão foi adicionado para cada $200 \mu \mathrm{L}$ de sêmen, para poder realizar as técnicas de Pour Plate, como preconiza a OIE (2005), e a contagem de bactérias viáveis por superfície. A partir do sêmen contaminado experimentalmente, observou-se equivalência no número de colônias bacterianas (UFC/mL) multiplicadas em ambas as técnicas, nas diluições de $10^{-1}$ a $10^{-5}$, sob as mesmas condições de cultivo.

Para comparação entre os resultados das técnicas Pour Plate e contagem de bactérias viáveis por superfície, foram quantificadas as médias em UFC/mL dos ejaculados, multiplicando-se o número de UFC pelo fator de diluição (Fig. 1 a 5).

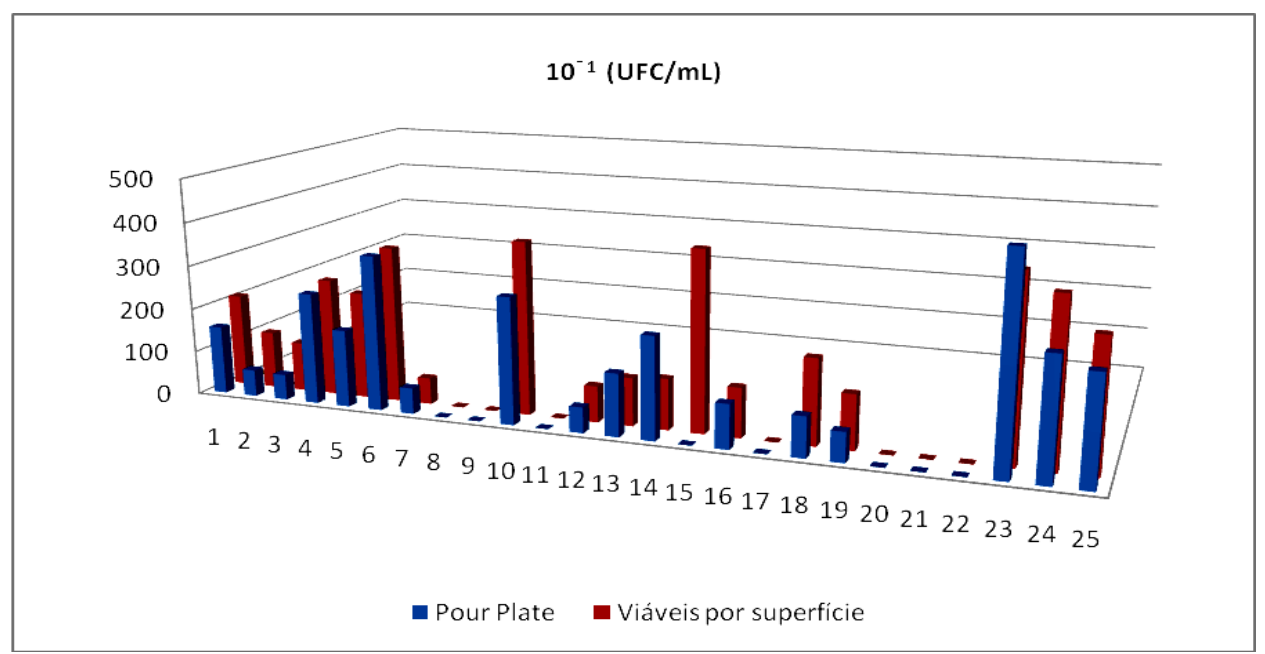

Figura 1. Valores de UFC/mL de 25 ejaculados contaminados com suspensões padronizadas de Staphylococcus spp., Acinetobacter spp. e Streptococcus spp. na diluição $10^{-1}$, observadas nas técnicas de Pour Plate e contagem de bactérias viáveis por superfície.

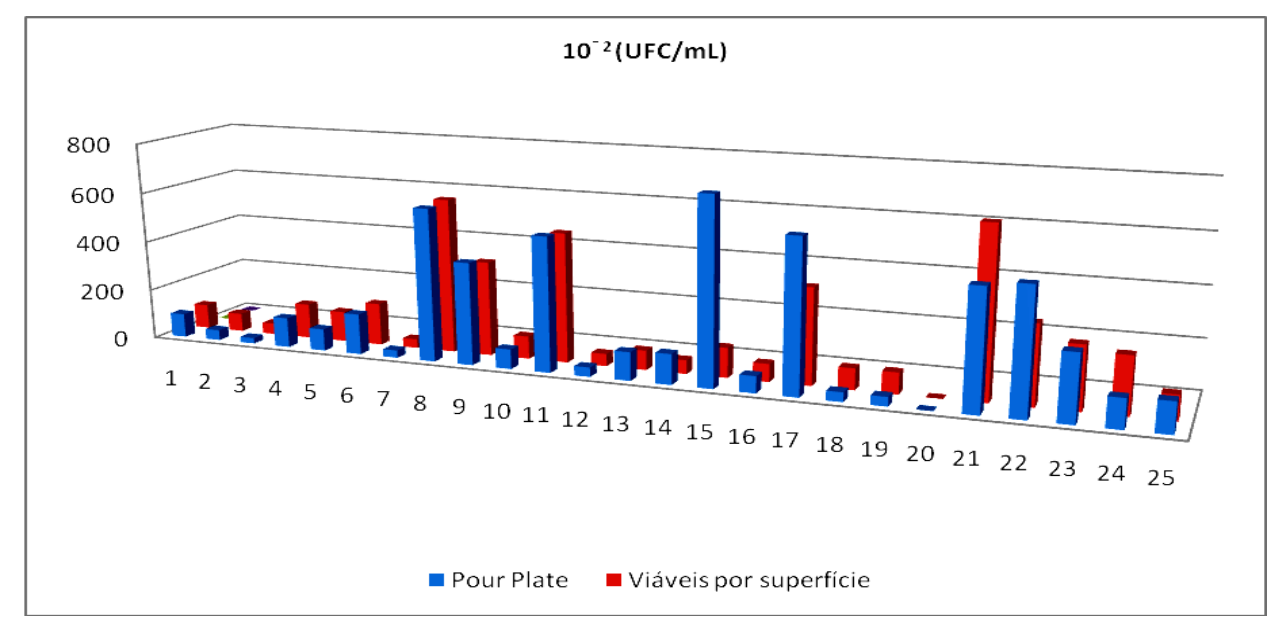

Figura 2. Valores de UFC/mL de 25 ejaculados contaminados com suspensões padronizadas de Staphylococcus spp., Acinetobacter spp. e Streptococcus spp., na diluição $10^{-2}$, observadas nas técnicas de Pour Plate e contagem de bactérias viáveis por superfície. 


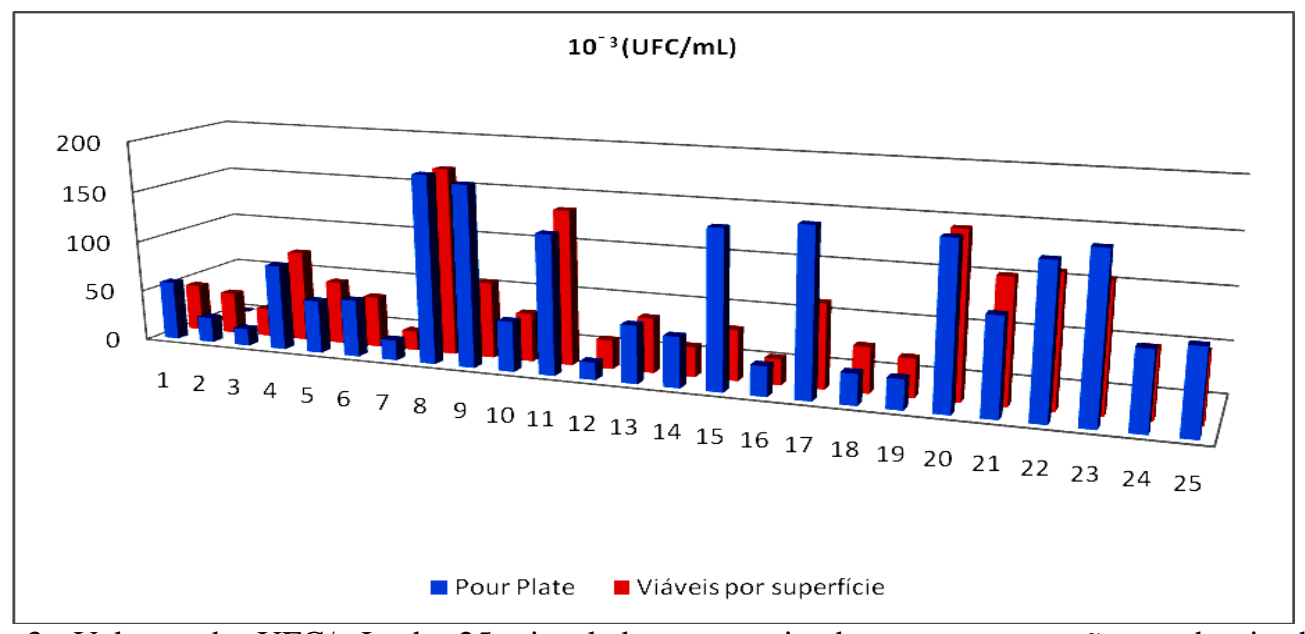

Figura 3. Valores de UFC/mL de 25 ejaculados contaminados com suspensões padronizadas de Staphylococcus spp., Acinetobacter spp. e Streptococcus spp., na diluição $10^{-3}$, observadas nas técnicas de Pour Plate e contagem de bactérias viáveis por superfície.

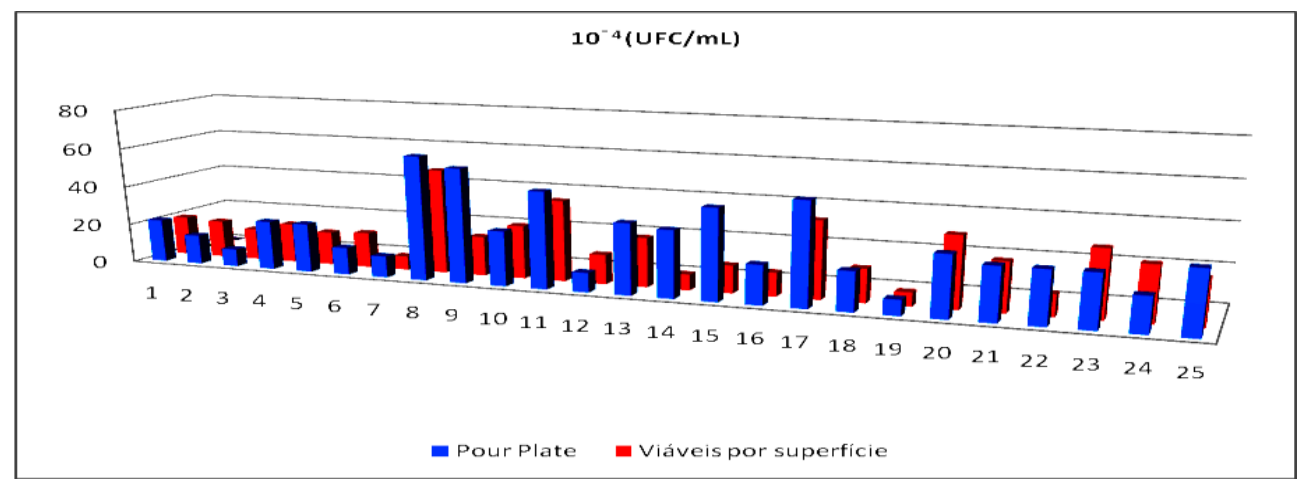

Figura 4. Valores de UFC/mL de 25 ejaculados contaminados com suspensões padronizadas de Staphylococcus spp., Acinetobacter spp. e Streptococcus spp., na diluição $10^{-4}$, observadas nas técnicas de Pour Plate e contagem de bactérias viáveis por superfície.

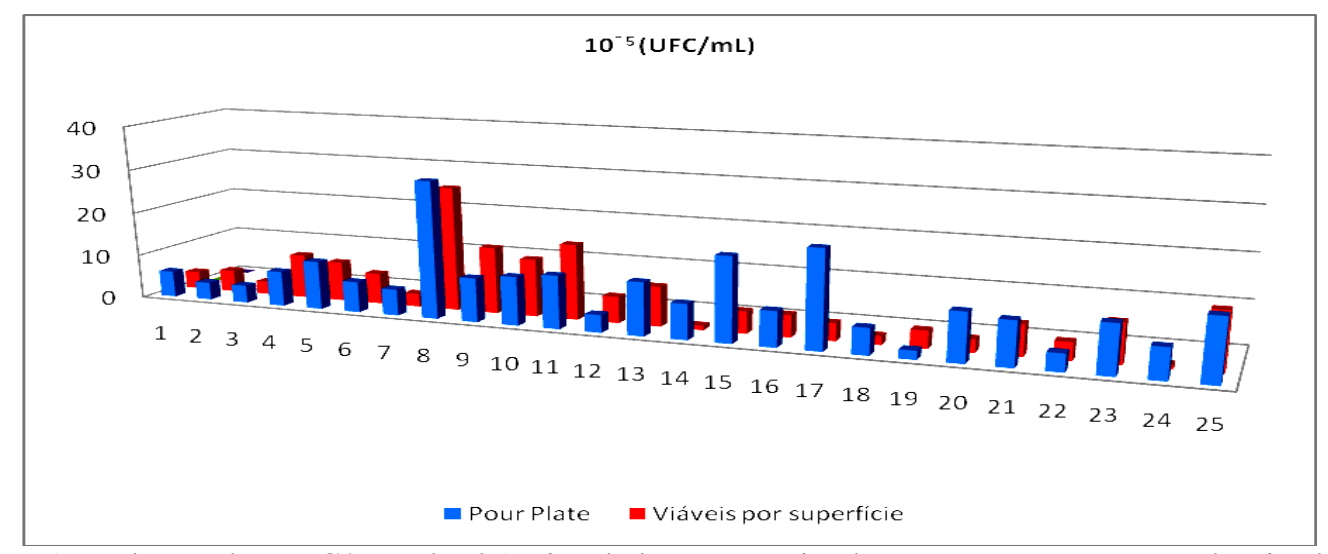

Figura 5. Valores de UFC/mL de 25 ejaculados contaminados com suspensões padronizadas de Staphylococcus spp., Acinetobacter spp. e Streptococcus spp., na diluição $10^{-5}$, observadas nas técnicas de Pour Plate e de contagem de bactérias viáveis por superfície. 
Na Tab. 1, são apresentados os resultados da análise estatística dos exames bacteriológicos quantitativos pelas técnicas de Pour Plate e contagem de bactérias viáveis por superfície em $\mathrm{UFC} / \mathrm{mL}$ das diluições contaminadas com suspensão padronizada de bactérias ubiquitárias. Nesta análise, não foram incluídas, em uma ou ambas as técnicas, as amostras que resultaram em quantidade de UFC incontáveis, sendo selecionadas apenas as que apresentaram crescimento de até 300UFC. Os valores em $\mathrm{UFC} / \mathrm{mL}$ não apresentaram diferença estatística $(\mathrm{P}>0,05)$ entre as duas técnicas nas cinco diluições.

Tabela 1. Análise estatística dos exames bacteriológicos quantitativos pelas técnicas de Pour Plate e contagem de bactérias viáveis por superfície em UFC/mL das diluições contaminadas com suspensão padronizada de bactérias ubiquitárias

\begin{tabular}{ccccc}
\hline Diluição & \multicolumn{2}{c}{ Pour Plate } & \multicolumn{2}{c}{ Contagem de bactérias viáveis por superfície } \\
\cline { 2 - 5 } & $\mathrm{N}$ & $\begin{array}{c}\text { Média } \pm \text { desvio-padrão ou } \\
\text { mediana } \pm \text { intervalo interquartil }\end{array}$ & $\mathrm{N}$ & $\begin{array}{c}\text { Média } \pm \text { desvio-padrão ou } \\
\text { mediana } \pm \text { intervalo interquartil }\end{array}$ \\
\hline $10^{-1}$ & 17 & $180,2 \pm 120,0$ & 17 & $216,2 \pm 124,7$ \\
$10^{-2}$ & 24 & $118,0 \pm 362,0$ & 24 & $109,0 \pm 188,7$ \\
$10^{-3}$ & 25 & $58,0 \pm 114,0$ & 25 & $53,0 \pm 48,0$ \\
$10^{-4}$ & 25 & $28,3 \pm 15,3$ & 25 & $22,1 \pm 11,4$ \\
$10^{-5}$ & 25 & $8,0 \pm 5,0$ & 25 & $5,0 \pm 5,0$ \\
\hline
\end{tabular}

Não houve diferença entre as técnicas de contagem de bactérias viáveis por superfície em UFC/mL.

\section{DISCUSSÃO}

A avaliação da qualidade do sêmen é crucialmente importante para a exploração de touros geneticamente superiores em um programa de inseminação artificial (Anzar et al., 2009). Alguns países importadores de sêmen exigem exames de espermocultura visando à detecção de microrganismos ubiquitários e oportunistas, destacando-se Pseudomonas spp., Proteus spp., Staphylococcus spp., Streptococcus spp., Escherichia coli e alguns fungos. Estes microrganismos podem estar presentes na cavidade prepucial e contaminar o sêmen durante a colheita. Na colheita de sêmen com vagina artificial, também pode haver contaminação com bactérias do exterior da genitália (OrtegaFerrusola et al., 2009), bem como no processamento e armazenagem do sêmen, pelo uso de fômites e equipamentos mal esterilizados, nitrogênio líquido contaminado, diluente contaminado por agentes ambientais ou mesmo oriundo da gema de ovos que compõe sua fórmula, ou do próprio manipulador (Thibier e Guerin, 2000), que deve ter experiência na colheita e tratamento do ejaculado para que não ocorra contaminação cruzada (Prado e Pérez, 2005). Deste modo, no uso da inseminação artificial, é importante o eficiente controle da população de microrganismos presentes no prepúcio e região perineal do touro, no ambiente de colheita e preparo do sêmen, para que seja possível prevenir a desqualificação da amostra, garantindo, além da biosseguridade à fêmea bovina e ao rebanho, a produtividade e a comercialização tanto nacional quanto internacional (Thibier e Guerin, 2000).

A inseminação artificial contribui para o controle e a prevenção de certas doenças, no entanto, quando os seus fundamentos de biossegurança não são atendidos, pode se tornar um fator de risco importante na transmissão de patógenos e na disseminação de microrganismos.

O emprego do sêmen congelado permitiu o intercâmbio do material genético sem limitações geográficas, entretanto os crioprotetores utilizados para a preservação dos espermatozoide, também mantêm os agentes microbianos. Somente por meio de rigoroso controle da saúde do doador, bem como das condições ambientais de colheita e de manipulação laboratorial é possível garantir a qualidade do sêmen (Prado e Pérez, 2005).

Sob certas condições ambientais, algumas bactérias oportunistas por via ascendente atingem o útero causando endometrites (Thibier e Guerin, 2000), interferindo na concepção ou mesmo levando a mortalidade embrionária ou ao abortamento (Eaglewsome e Garcia, 1992; Genovez et al., 1999; Gotti, 2006). Por serem geralmente ocorrências pontuais, denotam problemas com o sistema de manejo do rebanho (Scarcelli et al., 2004). 
Experimentos com filtrados de estafilococos e de Pseudomonas aeruginosa mostraram efeito nocivo sobre o desenvolvimento in vitro do embrião de rato (Meyer et al., 1980; Wierzbowski et al., 1980). A presença de Staphylococcus spp. em sêmen industrializado de touros está fortemente associada à manipulação pelo homem (Genovez et al., 1999).

Mesmo sob as melhores e mais adequadas condições de colheita, o sêmen in natura apresenta certa contaminação microbiana, geralmente entre 150.000 e 650.000 microrganismos $/ \mathrm{mL}$. Até o ano de 2005, a OIE preconizava que a contagem bacteriana do sêmen industrializado fornecia a indicação dos procedimentos higiênicos da central produtora e não deveria ultrapassar $5 \times 10^{3}$ bactérias por $\mathrm{mL}$ de sêmen. Entretanto, a indefinição do papel de bactérias da microbiota de prepúcio e ubiquitárias sobre a capacidade fecundante do sêmen, e ainda sobre a possibilidade de causar infecção em fêmeas bovinas, alterou as recomendações atuais da OIE sobre a colheita, higiene e manipulação do sêmen in natura e industrializado, não sendo mais definida a quantidade limite de microrganismos por $\mathrm{mL}$ de sêmen aceitável para uso em inseminação artificial. Por outro lado, a contaminação bacteriana presente no sêmen rotineiramente utilizado para inseminação artificial tem se mostrado limitante para o sucesso da técnica de fertilização in vitro (FIV), particularmente no momento do cocultivo. Pequenas quantidades de agentes ubiquitários, de microbiota autóctone ou mesmo oportunistas são francamente multiplicados nas condições empregadas na FIV.

Técnicas quantitativas parecem pouco prováveis de serem utilizadas como rotina em CIAs, principalmente Pour Plate, como recomendou a OIE até 2005. A contagem de bactérias viáveis por superfície poderia ser aplicada em casos específicos, devido a sua praticidade de execução e mais baixo custo.

\section{CONCLUSÕES}

Foi possível avaliar com confiabilidade as técnicas de Pour Plate e contagem de bactérias viáveis por superfície. Uma vez que não foi observada diferença estatística nas contagens entre as duas técnicas, sugere-se a real possibilidade de substituição da técnica de Pour
Plate pela contagem de bactérias viáveis por superfície em UFC/mL, com vantagens de praticidade e menor custo.

\section{AGRADECIMENTOS}

Agradecemos ao Ministério da Agricultura, Pecuária e Abastecimento (MAPA) pela doação das palhetas de sêmen bovino, referentes ao Projeto Hungria do Programa de Desenvolvimento da Bovinocultura de Leite.

\section{REFERÊNCIAS}

ANZAR, M.; KROETSCH, T.; BUHR, M.M. Comparison of different methods for assessment of sperm concentration and membrane integrity with bull semen. J. Androl., v.30, p.661-668, 2009.

BRASIL. Ministério Da Agricultura, Pecuária E Abastecimento. Programa de Desenvolvimento da Bovinocultura de Leite - Projeto Hungria, 2005. Disponível em: <http://www.agricultura.gov.br>. Acessado em: 10 set. 2005.

COELHO, N.M. Flora bacteriana do prepúcio e sêmen de reprodutores Bos taurus. 1976. 56f. Dissertação (Mestrado em Medicina Veterinária). Escola de Veterinária, Universidade Federal de Minas Gerais, Belo Horizonte.

EAGLESOME, M.D.; GARCIA, M.M. Microbial agents associated with bovine genital tract infections and semen. Part I. Brucella abortus, Leptospira, Campylobacter fetus and Tritrichomonas foetus. Vet. Bull., v.62, p.743753, 1992.

EAGLESOME, M.D.; GARCIA, M.M.; STEWART, R.B. Microbial agents associated with bovine genital tract infections and semen. Part II. Haemophilus somnus, Mycoplasma spp. and Ureaplasma spp., Chlamydia pathogens and semen contaminants; treatment of bull semen with antimicrobial agents. Vet. Bull., v.62, p.887910, 1999.

FLATSCHER, J.; HOLZMANN, A. Genital diseases in bulls: importance of artificial inseminationcontrol measures. In: CONFERENCE OF THE OFFICE INTERNATIONAL DES EPIZOOTIES, Regional Commission for Europe, Vienna. 1984, p.393-402. 
GENOVEZ, M.E.; SCARCELLI, E.; PICONE, A.B. Avaliação de dois métodos de coleta de muco prepucial no diagnóstico da campilobacteriose genital bovina. Biológico, v.52, p.7-11, 1986.

GENOVEZ, M.E.; SCARCELLI, E.P.; FACIOLLI, M.R. et al. Avaliação bacteriológica de sêmen in natura industrializado de touros. Rev. Bras. Reprod. Anim., v.23, p.403-405, 1999.

GOTTI, T.B. Avaliação de três protocolos antibióticos na qualidade do sêmen bovino quanto ao seu efeito sobre a microbiota autóctone e na destruição da Leptospira spp. sorovares Hardjo (estirpes Hardjoprajitno $e$ Hardjobovis) e Wolffi (estirpe 3705). 2006. 89f. Dissertação (Mestrado em epidemiologia experimental e aplicada às zoonoses) Faculdade de Medicina Veterinária e Zootecnia, Universidade de São Paulo, SP.

MASSAD, E.; MENEZES, R.X.; SILVEIRA, P.S.P.; ORTEGA, N.R.S. (Eds.). Métodos quantitativos em medicina. São Paulo: Manole, 2004. 570p.

MEYER, M.; SONNERSCHEIN, B.; BISPING, W.; KRAUSE, D. Studies on the pathogen effect of metabolic products of Staphylococcus aureus strains on bull semen. Berl. Munch. Tierarztl. Wochenschr., v.93, p.66-74, 1980.

OFFICE international des epizooties. Terrestrial animal health code. Bovine and small ruminant semen. 14.ed. 2005. Disponível em: <http://www.oie.int/eng/normes/mcode/en_chapi tre_3.2.1.htm>. Acessado em: 4 fev. 2005.

ORTEGA-FERRUSOLA， C.; GONZALEZFERNANDEZ, L.; MURIEL, A. et al. Does the microbial flora in the ejaculate affect the freezeability of stallion sperm? Reprod. Dom. Anim., v.44, p.518-522, 2009.

PALIT, A.; HAYLOCK, L.M.; COX, S.C. Storage of pathogenic leptospires in liquid nitrogen. J. Appl. Bacteriol., v.61, p.407-411, 1986.
PRADO, E.A.S.; PEREZ, R.M. Flora bacteriana del semen de toro antes e después de la congelación. Rev. Eletrón. Vet., v.VI, p.1-8, 2005.

QUINN, P.J.; CARTER, M.E.; MARKEY, B.; CARTER, G.R. (Eds.). Clinical veterinary microbiology. Virginia: Elsevier Health Sciences, 1994. 648p.

RODRIGUES, A.L.R. Avaliação das floras aeróbia e anaeróbia facultativa prepucial $e$ seminal de touros Bos indus submetidos à higienização intraprepucial em central de inseminação artificial. 1998. 86f. Dissertação (Mestrado em Medicina Veterinária). Faculdade de Medicina Veterinária e Zootecnia, Universidade Estadual Paulista Júlio de Mesquita Filho, São Paulo.

SCARCELLI, E.; PIATTI, R.M.; CARDOSO, M.V. et al. Detecção de agentes bacterianos pelas técnicas de isolamento e identificação e PCR - Multiplex em fetos bovinos abortados. Rev. Bras. Reprod. Animal. v.28, p.23-27, 2004.

THIBIER, M.; GUERIN, B. Hygienic aspects of storage and use of semen for artificial insemination. Anim. Reprod. Sci., v.62, p.233$251,2000$.

VARNER, D.D.; SCALAN, C.M.; THOMPSON, J.A. et al. Bacteriology of preserved stallion semen and antibiotics in semen extenders. Theriogenology. v.50, p.559-573, 1998.

WENTINK, G.H.; FRANKENA, K.; BOSCH, J.C. et al. Prevention of disease transmission by semen in cattle. Livest. Prod. Sci., v.62, p.207220, 2000 .

WIERZBOWSKI， S.; NOWAKOWSKI，W.; SMORAG, Z.; KATSKA, L. The influence of bacterial toxins on embryo development in vitro. In: INTERNATIONAL CONGRESS ANIMAL REPRODUCTION AND AI, 9., 1980. Madrid. Proceedings... Medrid: 1980. p.573-576.

ZAR, J.H. (Ed.). Biostatistical analysis. Prentice Hall: Upper Saddle River, 1999. 929p. 